This is a self-archived version of an original article. This version may differ from the original in pagination and typographic details.

Author(s): Jukka, Tapio

Title: Top management team demography and firm operating performance : a path analysis

Year: 2021

Version: Accepted version (Final draft)

Copyright: @ Emerald Publishing Limited, 2020

Rights: $C C$ BY-NC 4.0

Rights url: https://creativecommons.org/licenses/by-nc/4.0/

Please cite the original version:

Jukka, T. (2021). Top management team demography and firm operating performance : a path analysis. Journal of Strategy and Management, 14(1), 19-34. https://doi.org/10.1108/JSMA-122019-0224 
Top management team demography and firm operating performance: A path analysis

Tapio Jukka

Jyvaskyla University School of Business and Economics, University of Jyvaskyla, Box 35, FI40014 University of Jyvaskyla, Finland. E-mail: tapio.j.jukka@student.jyu.fi.

Corresponding author

Tapio Jukka E-mail: tapio.j.jukka@student.jyu.fi

Acknowledgments

This research was supported by University of Jyvaskyla grants 1/13.00.04.00/2015 and 2018 awarded to Tapio Jukka. The funding source was not involved with the research. 


\begin{abstract}
Purpose - This paper examined the relationship between TMT demographic properties and firm performance using both diversity and level variables and measuring differing constructs of firm performance representing divergent strategies.
\end{abstract}

Design/methodology/approach - Structural equation modelling was used to test the relationships between TMT demographic properties and firm performance measured as return on net operating assets (RNOA) and its disaggregates profit margin (PM) and asset turnover (ATO). Data was from 89 Finnish firms during years 2008-2011 resulting in 320 observations.

Findings - TMT team tenure had associations with RNOA through both PM and ATO while TMT age, age diversity, firm tenure, firm tenure diversity, and team tenure diversity showed paths through ATO. TMT firm tenure diversity showed effects in opposing directions through PM and ATO.

Practical implications - The results help to understand and apply the separate effects of age, firm tenure, and team tenure on TMT and firm performance. These results also provide explanations how these TMT properties affect firm performance in diverse types of firms pursuing different strategies.

Originality/value - The results suggest that both diversity and level in a measured TMT demographic property are linked with firm performance and the effect can be in differing directions. These links go through differing paths when using disaggregated operational firm performance measures. Also, diversity in top management is not always beneficial since it can cause separation or conflict impairing performance.

Keywords top management team, upper echelons, team properties, firm performance, operating performance, disaggregation, path analysis

Paper type Research paper 


\section{Top management team demography and firm operating performance:}

\section{A path analysis}

\section{Introduction}

In order to understand why organisations do certain things, e.g., choice of strategy and the processes and mechanisms to implement it, we must focus on their most powerful actors (Hambrick, 2007). The top management team (TMT) is often seen as a dominant coalition of the most senior executives with authority and powers to guide the organisation towards success (Carpenter et al., 2004; Hambrick, 2007). The upper echelons theory (Hambrick and Mason, 1984) has been widely used to explore the effects of top management on firm performance. According to the upper echelons theory, the demographic characteristics of the top executives can be used as valid proxies of their cognitive states and the properties of the top executives can be aggregated as group properties and associated with the firm's strategic choices and performance.

Prior research has established the relationship between top management properties and firm performance (Carpenter et al., 2004; Certo et al., 2006; Hambrick, 2007). Much of the prior research has studied the relationship between the demographic properties of the top management and single firm performance measures (Certo et al., 2006), but the upper echelons theory has also been used to explore the relationship between top management properties and for example firm internationalisation, growth, strategic change, innovation, and management control (Hiebl, 2014; Kraiczy et al., 2015; Nielsen, 2010a). Although the effects of various top management properties have been researched, most studies have focused on TMT diversity and its positive effect on performance (Bromiley and Rau, 2016; Certo et al., 2006; Homberg and Bui, 2013). Diversity can also give rise to social categorising within a TMT, which can impair the positive effects of diversity or even cause a fall in performance (van Knippenberg et al., 2004). Literature on teams also suggest that performance could be more associated with the level of the team demographic property, e.g., team mean age, rather than its diversity (Bell et al., 2011).

TMT or organisation performance and business success have been often measured with return on assets (ROA) as it can be applied to different types of organisations and enables comparisons of varied industries (Kihn, 2010). Despite its popularity, ROA may be problematic as it pools operational and financing items (Nissim and Penman, 2001; Soliman, 2008). Burns et al. (2008) suggest that return on net operating assets (RNOA) is better suited to measure top management's operational performance. Since RNOA is calculated as the ratio of operating income to net operating assets, it focuses on operating performance and eliminates the effect of financing (Nissim 
and Penman, 2001; Soliman, 2008). Using DuPont analysis to further disaggregate RNOA into profit margin (PM) and asset turnover (ATO) leads to better measures of the TMT effect on firm performance as PM and ATO are products of differing firm strategies. PM is frequently an outcome of differentiation strategies and ATO of cost leadership strategies (Selling and Stickney, 1989; Soliman, 2008). This allows the examination whether the TMT's group task, i.e., differentiation or cost leadership, affects the TMT properties-performance link and extends our knowledge on how TMT demographic properties affect performance.

Despite the growing body of upper echelons research, the results from previous research are still inconclusive and mixed (Hambrick et al., 2015; Homberg and Bui, 2013; Nielsen, 2010a). This research extends our knowledge of the relationship between TMT demographic properties and firm performance by examining the effect of TMT age, firm tenure, and team tenure average and diversity on firm performance. Applying structural equation modelling, the mediating effect of the TMT's group task, i.e., differentiation or cost leadership, is also evaluated. This research contributes to existing literature on TMTs and upper echelons in several ways. First, the results suggest that both diversity and level in a measured TMT demographic property are linked with firm performance and the effect can be in differing directions. Second, the results show the differing paths between TMT properties and firm performance when using disaggregated operational performance measures that measure differing constructs of a firm's operations. Third, the findings suggest that diversity in top management is not always beneficial and may cause separation and conflict impairing performance.

The paper proceeds as follows. Theoretical background for the upper echelons theory and TMT is provided in the next section. The third section describes the data and methods used while the results are presented in section 4. Finally, discussion with conclusions and limitations of the study are presented in section 5 .

\section{Theoretical background and hypotheses}

\subsection{Upper echelons theory}

In order to understand why organisations do certain things we must focus on their most powerful actors with their biases and character (Hambrick, 2007). According to the upper echelons theory the top executives form personal interpretations of the strategic challenges they face, and act based on these interpretations. These personal constructs are a function of the executives' experiences, values, and personalities (Hambrick, 2007). The TMT is the organisation tier ultimately responsible for the success of the organisation and TMT properties have been linked with the organisation's 
strategic or operational decision-making and the following results (Carpenter et al., 2004; Hambrick, 2007; Naranjo-Gil et al., 2008).

Pfeffer's organisational demography theory suggests that an organisational group can be studied as a unit through the properties of its members (Lawrence, 1997). It is possible to form one measure that reflects the behaviour of the group as one unit by collecting and combining data on the individual members. The upper echelons theory proposes that the properties of the TMT as a group explain the firm's performance better than the properties of its individual members (Hambrick, 2007). One person cannot manage and lead a large organisation alone. It is divided between the top executives thus making it a collective effort and drawing on the combined knowledge, capabilities, and interactions of everyone involved.

The upper echelons theory assumes that the executives' demographic properties can be used as proxies for their cognitive settings (Hambrick, 2007). This makes it possible to predict strategic actions from the executives' functional backgrounds, business or firm tenure, educational background, and other affiliations. The upper echelons literature has mostly focused on the effects of group diversity, but group performance could be more associated with the level of the group demographic property, e.g., mean age or tenure, than its diversity (Bell et al., 2011).

\subsection{Top management team}

The TMT can be seen as a dominant coalition consisting of the senior executives of an organisation (Carpenter et al., 2004). They provide an interface between the organisation and its environment, are powerful, and their decisions and actions influence the organisation. Central to the TMT research is defining the TMT and its members. In the dominant U.S. based upper echelons literature, the TMT construct and membership is often identified by position in the hierarchy or by job title, and the TMT is not seen as a real team (Glunk et al., 2001). In their meta-analysis Certo et al. (2006) identified various definitions for TMTs. The TMT consisted of a varying number of tiers or echelons of directors and top executives. Some studies have defined the TMT as the top executives not on the board of directors (Boeker, 1997; Naranjo-Gil and Hartmann, 2006; Smith et al., 2006). The TMT can also be defined as the executive team announced in the firm's annual reports (Nielsen and Nielsen, 2013). Adding to the confusion, the terms top management team and upper echelons have been used interchangeably (Yamak et al., 2014).

Although TMTs seldom work as real teams, they can integrate their behaviour and thus work more like teams (Hambrick, 2007). Boone and Hendricks (2009) also noted that the perception of TMTs as regularly meeting, discussing, exchanging ideas, and problem-solving teams can be misleading. 
Although they point out that to utilise its member's functional know-how, the TMT must co-operate and function more like a team. In this light it is appropriate to define the TMT as a team of executives declared by the firm. This definition is in line with the team concept of a social group who see themselves as a team and is also seen by outsiders as a team (Senior and Swailes, 2004).

\subsection{TMT demographics and performance}

The effects of team member demographic properties on team performance has focused on how differences or diversity affect team performance (Bell et al., 2011). Team or group diversity has been assumed to have positive or negative effects on performance depending on how it is conceptualized. Building on the information/decision-making perspective, van Knippenberg et al. (2004) suggest a categorisation-elaboration model of work group diversity and group performance. In their model, diversity in a group or team leads to different types of knowledge, decision-making models, and a wider range of perspectives, i.e., elaboration of the task-relevant information and perspectives. This in turn leads to better group performance especially in group creativity, innovation, and decision quality. In their model, diversity or differences between group members can also induce social categorisation, i.e., differentiation between the similar to self in-group and dissimilar to self out-group. Social categorisation may cause more positive responses to the ingroup than the out-group or intergroup biases. The negative effects of diversity on group performance are then caused by the intergroup biases interfering and disrupting the group diversityelaboration link (van Knippenberg et al., 2004).

The majority of the research on the team member demographic properties and team performance link has focused on diversity of the demographic variable and largely ignored other representations of the team level demographic variable (Bell et al., 2011). Although there is evidence showing a link between diversity and team performance, the effects are often hard to detect and small (Bell et al., 2011; Homberg and Bui, 2013). There is also evidence suggesting that the elevated level of a team demographic variable, e.g., mean age, has a stronger effect on team performance than diversity (Bell et al., 2011; Gonzalez-Mulé et al., 2020). Thus, elevated levels of team demographic properties may be more important predictors of team performance than diversity in these variables.

The performance metric used may also affect the link between team demographic properties and team performance. In spite of its popularity, ROA imposes problems when measuring the TMT influence on firm performance as it pools operational and financing items (Nissim and Penman, 2001; Soliman, 2008). RNOA is calculated as the ratio of operating income to net operating assets thus focusing on operating performance and eliminating the effect of financing (Nissim and 
Penman, 2001; Soliman, 2008) making it better suited to measuring the operational performance of the TMT (Burns et al., 2008). Using the Dupont analysis, RNOA can be disaggregated into the product of PM and ATO to better display the effect of the TMT (Fairfield and Yohn, 2001; Soliman, 2008). PM and ATO measure differing constructs of the firm's operations. PM is frequently an outcome of pricing power resulting from product innovation, product positioning, branding, first mover advantage, and market niches, often associated with differentiation strategies (Selling and Stickney, 1989; Soliman, 2008). Thus, TMTs pursuing innovation, creativity, and a wider range of perspectives would benefit from diversity and stress PM in performance measurement (Bell et al., 2011). On the other hand, ATO reflects asset utilisation and effectiveness following from effective use of fixed assets, efficient inventory processes, and working capital management, features of cost leadership strategies (Selling and Stickney, 1989; Soliman, 2008). When efficiency is the primary metric, TMTs would benefit from convergence and emphasise ATO (Bell et al., 2011).

\subsection{TMT age}

The TMT mean member age affects the team's performance because age can influence the way individuals behave and make decisions. Increasing age has long been linked with declining performance (Sturman, 2003). A simple explanation for the decline in performance is the deterioration of cognitive skills, e.g., learning, memory, and reasoning (Sturman, 2003). Ng and Feldman (2013) found that quick information processing, effective multitasking, and finishing tasks under pressure declined with increasing age. Although executives have been found to improve their management skills with age, but after the age of 45 increasing conservatism dwindles the positive effects (von den Driesch et al., 2015). Motivation can also be affected by increasing age as employees have been shown to lower their expectations and ambitions with increasing age (Sturman, 2003). Also, older executives start avoiding risks as financial and career security become more important, and oppose change as flexibility decreases and resistance increases (Wiersema and Bantel, 1992).

In sum, the decline in cognitive skills and lower motivation of older TMTs is expected to lead to lower firm performance with both differentiation and convergence type TMTs. The following hypotheses can be formed:

H1a: TMT age is negatively associated with firm PM.

H1b: TMT age is negatively associated with firm ATO. 
Although diversity is expected to bring about a wider range of perspectives leading to better decisions and performance, increasing age diversity may result in decreasing TMT performance due to social categorisation leading to intergroup biases that impede the positive effects of age diversity. Physical properties like age are easily observed and more significant than other less visible demographic properties in the early stages of group development (Pelled, 1996). According to Wiersema and Bantel (1992), age helps to predict a person's non-work-related experience, and people of similar age share common experiences that lead to shared attitudes and beliefs. Individuals take this information into account when categorising other team members into groups within the TMT (Bell et al., 2011).

Diversity in TMT age may cause divisions in the TMT and increase personal conflict hindering firm performance especially with TMTs seeking convergence and stressing ATO over PM. This leads to the following hypotheses:

H2a: TMT age diversity is negatively associated with firm PM.

H2b: TMT age diversity is (strongly) negatively associated with firm ATO.

\subsection{TMT firm tenure}

A long tenure in the same organisation unifies its members' values and norms as the individual adopts the surrounding culture (Abebe, 2010). This socialisation generates common procedures for scanning the environment and processing information. A longer firm tenure also gives better knowledge and understanding of the organisation's norms and functions resulting in better performance of the team when efficiency is the measure (Bell et al., 2011). In addition, increasing firm tenure can also integrate the TMTs behaviour similar to the effect of team tenure by creating common perspectives and operating models (Hambrick, 2007). On the downside, long tenured executives tend to maintain the status quo by adhering to existing routines and resisting change leading to weaker performance if changes or new ideas are needed (Abebe, 2010; Boeker, 1997). This suggests long firm tenures could impair performance of the team when pursuing innovation, creativity, and a wider range of perspectives (Bell et al., 2011).

Thus, long tenure in the same organisation integrates and unifies the TMTs behaviour and decreases the top managements urge to change the status quo. This would impair the performance of firms with innovative and differentiation strategies but improve the performance of firms seeking effectiveness and cost leadership strategies. Hence, it can be hypothesised: 
H3a: TMT firm tenure is negatively associated with firm PM.

H3b: TMT firm tenure is positively associated with firm ATO.

Persons that have served in the same organisation or task for extended periods develop common procedures for scanning the environment, processing information, and functioning within an organisation's culture (Sturman, 2003). In firm tenure diverse teams this organisational socialisation has taken place at different times and team members have greater variety of perspectives in terms of organisational know-how (Bell et al., 2011). Thus, increasing firm tenure diversity is a source for diverse and better decisions leading to improved firm performance (Hambrick et al., 1993; van Knippenberg et al., 2004). According to Bell et al. (2011), this diversity in perspectives would benefit innovative organisations seeking differing views. Increasing firm tenure diversity is also linked with poor firm performance when efficiency and routine tasks are emphasised. As van Knippenberg et al. (2004) pointed out, all types of diversity can elicit social categorisation resulting in intergroup biases that have a negative impact on performance. Thus, when teams seek effectiveness and convergence, diversity in perspectives can induce conflict and separation resulting in impaired performance (Bell et al., 2011).

Increasing firm tenure diversity brings in diverse perspectives improving the performance of firms with innovative and differentiation strategies. The increased diversity also inhibits convergence and unity in decision making of effectiveness-oriented firms. The following hypotheses can be drawn:

H4a: TMT firm tenure diversity is positively associated with firm PM.

H4b: TMT firm tenure diversity is negatively associated with firm ATO.

\subsection{TMT team tenure}

Increasing team tenure has notable effects for a team and its performance. Team tenure has been shown to have a positive effect on team performance and this link is mediated by team cognition (Gonzalez-Mulé et al., 2020). Team cognition refers to how important knowledge to team functioning is organised, represented, and distributed within the team, and allows team members to anticipate and execute actions (DeChurch and Mesmer-Magnus, 2010). Team cognition includes team mental models, i.e., knowledge that is held in common by team members, and the team's transactive memory system, i.e., knowledge of the information distribution within the team meaning who knows what (DeChurch and Mesmer-Magnus, 2010; Kozlowski and Ilgen, 2006). Team members have unique knowledge of the job, team, and organisation, and as team tenure increases, 
more knowledge is accumulated and the team can draw from it to accomplish its task (Gonzalez-Mulé et al., 2020). Thus, teams with longer team tenure can develop effective team cognition with time and improve performance (Gonzalez-Mulé et al., 2020).

Although a TMT might not work as a team, but more often through bilateral relationships with the CEO, it can increase mutual interaction by integrating its behaviour (Hambrick, 2007). By integrating its behaviour, a TMT can develop effective team cognition with increasing team tenure like a real team and improve performance. While, both differentiation and cost leadership firms would benefit from the accumulation of knowledge, increased knowledge about who knows what could benefit more a differentiation strategy with diverse perspectives. This leads to the following hypotheses:

H5a: TMT team tenure is (strong) positively associated with firm PM.

H5b: TMT team tenure is positively associated with firm ATO.

Team tenure diversity implies that the team members have joined the team at different points of time and are at dissimilar stages of the social integration process. When new team members are integrated into the team, they bring fresh ideas, new perspectives, and challenge existing methods, while more tenured team members offer information on current structures and practices (Bell et al., 2011). According to van Knippenberg et al. (2004) this diversity brings about different types of knowledge and perspectives leading to better group performance especially in group creativity, innovation, and decision quality. These are valuable outcomes for TMTs and firms emphasising differentiation strategies. On the other hand, group or team tenure is both a highly visible and highly job-related demographic variable potentially causing social categorisation within the team and possibly leading to both affective and substantive conflict (van Knippenberg et al., 2004; Pelled, 1996). This could have an adverse effect on the link between diversity and increased knowledge or perspectives resulting in lower performance (van Knippenberg et al., 2004). This would negatively affect the performance of TMTs or firms seeking cost leadership strategies with congruence and effectiveness (Bell et al., 2011).

TMT team tenure diversity is expected to bring about diverse ideas and perspectives improving performance of innovative TMTs. The diversity in team tenure can cause social categorisation and conflict in congruence seeking TMTs weakening their performance. From this the following hypotheses can be formed:

H6a: TMT team tenure diversity is positively associated with firm PM. 
H6b: TMT team tenure diversity is negatively associated with firm ATO.

Figure 1 illustrates the theoretical model and hypotheses.

Figure 1 about here

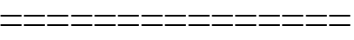

\section{Data and Methods}

\subsection{Data}

The sample was collected from the firms listed in the NASDAQ OMX Helsinki stock exchange during the years 2008-2011. The accounting information used to calculate firm performance was collected from the Voitto+ firm information database published by Suomen Asiakastieto Oy. The data was published in November 2012. This sample was chosen as Finnish companies readily publish information on their TMTs and the very interesting time period included both financial crisis and recovery. As U.S. samples dominate the upper echelons research (Homberg and Bui, 2013) this adds diversity to the research stream.

The TMT and its members were defined as what the firm reported. It was thus conceptualised as a real team identified by itself and outsiders. Information on the TMTs and their members was collected from the firms' audited annual reports. The information was supplemented with information from stock exchange releases, firm internet pages, and TMT member LinkedIn profiles. A six-month minimum tenure in a fiscal year was required to be counted as part of the TMT. It takes time to integrate a new team member and a leaving member may lack interest.

Data was collected from 89 firms in five industries (Table I). When data for a firm-year was missing, the firm-year was listwise deleted. This resulted in 330 firm-years of data. The Mahalanobis distance was used to detect outliers (Hair et al., 2015). Ten possible cases were found and after individual inspection all were dropped as deviant cases. The final sample consisted of 320 firm-years of data. This gave an acceptable ratio of 17.8 cases per estimated variable (Hair et al., 2015; Schreiber et al., 2006). The normality and linearity of the variate was checked visually and maximum VIF of 5.03 did not suggest multicollinearity (Hair et al., 2015). 


\section{Table I about here}

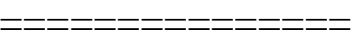

\subsection{Measures}

\section{Dependent variables}

The dependent variables in this study were based on accounting figures, since management has more influence on accounting-based measures than on market-based measures (Shen and Cannella, 2002). RNOA was calculated as operating income before interest divided by average net operating assets (NOA), where NOA is operating assets less operating liabilities (Soliman, 2008). Operating assets were total assets less cash and short-term investments. Operating liabilities were total assets less short and long-term debt, less book value of total equity, and less minority interest. RNOA was disaggregated into PM $\times$ ATO, where PM was operating income before interest divided by total sales and ATO was total sales divided by average NOA.

\section{Independent variables}

Age and firm tenure were calculated as simple means for each team. Following Hambrick (2007), the TMT was assumed to work through bilateral relationships with the CEO, and TMT team tenure was operationalised as how long the TMT members have been on the TMT with the CEO. The lengths of all these dyadic relationships within the TMT were averaged to define the TMT team tenure. Age, firm tenure, and TMT team tenure diversity were conceptualised as separation and in line with Harrison and Klein (2007), standard deviation was used as a measure. Since the group size of the data varied possibly causing systematic bias in the results, a bias corrected formula for standard deviation was used (Biemann and Kearney, 2010).

\section{Control variables}

TMT size affects the decision making dynamics of the team (Carpenter et al., 2004; Kraiczy et al., 2015), while firm size, industry, and year can affect firm performance (Barkema and Shvyrkov, 2007; Camelo et al., 2010; Nielsen, 2010b). These were therefore added as control variables. TMT size was measured as total number of TMT members. The logarithm of total number of employees was used to measure firm size. Industry dummies were added to control possible industry effects. The 89 firms in the sample were grouped into five industries based on their ICB classification: (1) 
basic materials, (2) consumer goods, (3) consumer services, (4) industrials, and (5) technology. Year dummies were added to control for temporal effects.

\subsection{Analysis}

Structural equation modelling (SEM) was applied using the SPSS AMOS 26 software to test the hypothesised relationships between the measured TMT properties and firm performance indicators. SEM can examine a series of relationships simultaneously and is useful in testing models containing multiple equations involving dependence and mediation relationships. The structural model and path coefficients were estimated using maximum likelihood estimation as it is widely used and robust against violations of the normality assumptions (Hair et al., 2015).

\section{Results}

Means, standard deviations, and correlations of the key variables are presented in Table II.

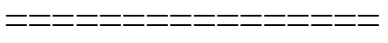

Table II about here.

Results of the structural equation modelling are presented in Table III. The hypothesised model received substantial support and displayed good fit to the data. The fit indices $\left(X^{2}=37.17, \mathrm{df}=16\right.$, $\mathrm{p}=0.002 ; \mathrm{CFI}=0.99 ; \mathrm{NFI}=0.98 ; \mathrm{RMSEA}=0.064 ; \mathrm{SRMR}=0.013)$ all showed acceptable goodness-of-fit (Hair et al., 2015; Schreiber et al., 2006). The proportions of variance explained by the model in PM, ATO, and RNOA were respectively 0.18, 0.25, and 0.77.

Table III about here.

Hypotheses 1a and 1b predicted a negative association between TMT age and firm PM and ATO, respectively. As shown in Table III, the standardised path coefficients were in the hypothesised direction and ATO was significant $(\beta=-0.09 ; \beta=-0.22, \mathrm{p}<0.01)$. These results supported hypothesis $1 \mathrm{~b}$. Hypothesis $2 \mathrm{a}$ asserted a negative association between TMT age diversity and firm PM. Although the path coefficient from TMT age diversity to firm PM (Table III) was in the negative direction $(\beta=-0.03)$, it was not significant, and hypothesis $2 \mathrm{a}$ was not supported. Similarly, hypothesis $2 \mathrm{~b}$ predicted a strong negative association between TMT age diversity and 
firm ATO. Table III shows that the path coefficient from TMT age diversity to firm ATO was in the asserted direction and strongly significant $(\beta=-0.20, p<0.01)$, thus supporting hypothesis $2 b$.

Hypothesis 3 a predicted a negative association between TMT firm tenure and firm PM. Table III shows that the standardised path coefficient from TMT firm tenure to firm PM was in the predicted direction $(\beta=-0.01)$ and statistically not significant. Thus, hypothesis $3 \mathrm{a}$ was not supported. As predicted in hypothesis $3 \mathrm{~b}$ and shown in Table III, TMT firm tenure was positively associated with firm ATO $(\beta=0.19, \mathrm{p}<0.05)$. The path coefficient was statistically significant and hypothesis $3 \mathrm{~b}$ was supported. Hypothesis 4a proposed a positive association between TMT firm tenure diversity and firm PM. Table III shows that the path coefficient from TMT firm tenure diversity was in the predicted direction $(\beta=0.11)$ but not significant. Therefore, hypothesis $4 \mathrm{a}$ was not supported. Hypothesis $4 \mathrm{~b}$ predicted that TMT firm tenure diversity is negatively related to firm ATO. The standardised path coefficient between the variables (Table III) was in the predicted direction and statistically significant $(\beta=-0.15, \mathrm{p}<0.05)$ supporting hypothesis $4 \mathrm{~b}$.

Hypotheses $5 \mathrm{a}$ and $5 \mathrm{~b}$ predicted a positive association between TMT team tenure and firm PM and ATO. As Table III shows, both path coefficients from TMT team tenure to firm PM and ATO were in the predicted direction and statistically significant $(\beta=0.16, \mathrm{p}<0.05 ; \beta=0.17, \mathrm{p}<0.05)$ lending support for hypotheses $5 \mathrm{a}$ and $5 \mathrm{~b}$. Hypotheses $6 \mathrm{a}$ asserted a positive relationship between TMT team tenure diversity and firm PM. The standardised path coefficient (Table III) from TMT team tenure diversity to firm PM was in the predicted direction $(\beta=0.07)$ but statistically not significant. Thus, hypothesis $6 \mathrm{a}$ lacked support. Hypothesis $6 \mathrm{~b}$ asserted a negative relationship between TMT team tenure diversity and firm ATO. The standardised path coefficient (Table III) from TMT team tenure diversity to firm ATO was also negative and statistically significant $(\beta=-0.14, p<0.10)$ supporting hypothesis $6 \mathrm{~b}$.

In summary, these results suggest that the properties of the top management affect firm performance, but through different paths. While seven of the proposed twelve distinct hypotheses were supported, it should be noted that all six measured TMT properties had a significant effect on RNOA either through PM or ATO. TMT team tenure had significant associations with RNOA through both PM and ATO. TMT age, age diversity, firm tenure, firm tenure diversity, and team tenure diversity showed paths through ATO affecting RNOA. Interestingly, TMT firm tenure diversity showed effects in opposing directions when the path went through PM or ATO. 


\section{Discussion and Conclusions}

This paper examined the relationship between TMT demographic properties and firm performance using both level and diversity demographic variables, and measuring differing constructs of firm performance representing differentiation and cost leadership strategies. The results suggest that firm performance could be more associated with the level of the TMT demographic property rather than its diversity and that TMT properties are associated with firm performance through differing paths representing differing strategies.

As expected, increasing TMT age had a negative effect on firm performance. The effect of increasing age and the deterioration of cognitive skills could be seen in both declining PM and ATO. These results support earlier findings on the effect of age (Chen, 2011; Sturman, 2003). Also, the mean age of the sample was 47.5 years placing it well into the declining part of age/performance curve (von den Driesch et al., 2015). Interestingly, increasing age had a stronger negative effect when pursuing a cost leadership strategy and measuring ATO than when pursuing a differentiation strategy and measuring PM. Ng and Feldman (2013) suggest the accumulation of experience and tacit knowledge make up to some extent for the decline in cognitive skills when aging. This might be beneficial when seeking a wider range of perspectives and measuring PM instead of seeking for congruence and measuring ATO.

Although TMT age diversity is expected to bring about elaboration and lead to better team performance (van Knippenberg et al., 2004), the social categorising leading to intergroup biases interferes with this link and impairs team performance. The effect was strong with congruence seeking TMTs measuring ATO and pursuing a cost leadership strategy. This supported Bell et al. (2011) notion that age diversity promotes separation and could be detrimental to team performance. On the other hand, the separation and personal conflict did not seem so detrimental when pursuing a differentiation strategy and measuring PM, the induced intergroup biases seemed to only cancel the positive effects expected from diversity. This suggests that the effects of diversity depend on what type of strategy the firm is pursuing.

Contrary to expectations, this study did not find a significant negative association between TMT firm tenure and PM. The effect was small and in the expected direction. On the other hand, the association with ATO was significant and suggests improved performance with increasing firm tenure. These results support the view that long firm tenures socialise or integrate organisation members and unify behaviours and perspectives. These uniform views promote convergence resulting in better performance when cost leadership and effectiveness strategies are pursued (Bell 
et al., 2011; Hambrick, 2007). Unified views, accrued organisational know-how, and common communication practices do not seem to affect performance when differentiation and a wider range of perspectives are valued. Instead, when differentiation is key, diversity in firm tenure seems to improve performance as task-relevant information and perspectives are elaborated (van Knippenberg et al., 2004). When convergence is sought, elaboration of information and wider range of perspectives might not be beneficial and team performance does not improve with diversity. Instead, social categorisation may induce intergroup biases impairing performance. This finding underpins the relevance of the team's task, whether it is elaboration or convergence, and its effect on the diversity-performance link.

As expected, TMT team tenure was positively associated with firm performance. This finding supports findings in prior studies that TMTs integrate their behaviour or act more like a team resulting in improved performance (Bell et al., 2011; Hambrick, 2007). Thus, teams with longer team tenures develop effective team cognition with time as knowledge is accumulated and its distribution within the team is recognised and this is reflected in improved performance (Gonzalez-Mulé et al., 2020). Although differentiation was expected to benefit more from the increase in team tenure, the increase in performance was the same when measuring PM than ATO. Both differentiation and convergence benefit from the accumulation of knowledge within the team and the developments in the team's transactive memory system, i.e., increased awareness of who knows what. As Hambrick (2007) has noted, TMTs do not work as real teams, but more through bilateral relations with the CEO. When the interactions within the TMT are centralised around the CEO and there is little interaction between the other TMT members, increased knowledge about who knows what within the TMT could be restricted limiting the benefits for differentiation compared to convergence.

Diversity in TMT team tenure had a positive effect on PM and a negative effect on ATO. Although the effect was weak, the positive effect of team tenure diversity on PM suggests TMTs and firms pursuing differentiation strategies are able to utilise the different types of knowledge and perspectives resulting from the differences in tenures. The negative effect on ATO was expected. Even though diversity brings about different types of knowledge and perspectives leading to improved performance, the introduction of new team members leading to diverse team tenures can elicit social categorisation and cause a decline in performance when convergence is important. The strong effect of social categorisation might be caused by the way TMTs work. Hambrick (2007) noted that TMTs work through bilateral relations mainly with the CEO not really forming a team, but could integrate their behaviour with time. In such surroundings, social categorisation could be 
more potent than within a real team. This is supported by Roh et al. (2019) findings that task- and relations-oriented diversity in TMTs increase relational conflict while reducing team cohesion, behavioural integration, and strategic consensus thus affecting negatively firm performance. Although variety induced by team tenure could improve performance in teams (Gonzalez-Mulé et al., 2020), it can impair performance in TMTs (Roh et al., 2019).

This study makes several contributions to existing knowledge on upper echelons and TMTs. First, the results suggest that not only diversity in the top management explains differences in firm performance. Although, diversity in a measured demographic property might be associated with firm performance, the level of this variable can have a stronger association with firm performance. Also, the association can be in opposing directions, e.g., the positive effects of increasing team tenure may be reversed by the negative effects of increasing team tenure diversity. Second, the current results highlight the importance of using variables that measure operating performance of the top management. Disaggregating these measures further to measure differing constructs of a firm's operations shows the different paths between TMT properties and firm performance. The varied size and direction of the association between TMT properties and the more detailed measures may help to explain the mixed and not significant results from prior research. Third, the findings suggest that diversity in top management is not always beneficial. Although diversity is often conceptualised as invoking new knowledge and perspectives leading to improved performance, it can also induce social categorisation and intergroup biases that impair performance (van Knippenberg et al., 2004) contingent on the TMTs need for divergence or convergence.

\subsection{Managerial implications}

This study also provides practical insights for executive groups and boards of directors. The results help to understand and utilise the separate effects of age, firm tenure, and team tenure on TMT and firm performance. While increasing firm and team tenures were found to have positive effects, increasing age works in the opposite direction. This suggests that adding young new TMT members with long firm tenures would be beneficial to TMT performance. On the other hand, avoiding changes and increasing team tenure would also improve performance.

The present study also demonstrates the effects of diversity on performance in different contexts. In general, diversity is expected to lead to elaboration of new ideas and wider perspectives resulting in better performance while social categorisation leads to intergroup biases that interfere with the diversity-elaboration link impairing performance (van Knippenberg et al., 2004). The results suggest TMTs of firms pursuing cost leadership strategies and effectiveness valuing convergence 
are especially prone to social categorising within the TMT. This results in lower performance when age, firm tenure, and team tenure diversity increases. Firms pursuing innovation, creativity, and wider range of perspectives are less affected by social categorising and diversity can improve performance.

\subsection{Limitations and directions for future research}

While the results expand our knowledge on TMT and firm performance, there are limitations to this study. Considerable effort was made to collect a representative sample and avoid biases. Although the data consists of firms from five industries with multiple firms in each industry, it is a nonprobability sample from a single country. This could decrease the generalisability of the results. RNOA and its disaggregates were chosen as performance measures to focus on the operational performance of the top management. Despite the suitability of the measures, the industry could cause categorisation in the sample and bias the results. Further studies in other countries using single and multiple industry data are therefore recommended. Also, the disaggregation of PM and ATO further might produce interesting results.

Although the Finnish business culture is near to other European business cultures, it might affect the results. The Finnish business culture is characterised by low power distance and high individualism (Hofstede, 2001). Low power distance implies low hierarchies, equal rights, and accessible superiors. On the other hand, high individualism suggests formal employer/employee relations and management is management of individuals. This might influence the bilateral relations within the TMTs.

The TMT was defined as the group the firm and the executives themselves perceive as the TMT in line with the definition of a team (Senior and Swailes, 2004). This however differs from most upper echelon studies where the research object is a fixed number of executive tiers seen from the outside. Diversity was conceptualised as separation along the guidelines of Harrison and Klein (2007). Also, the bias corrected measure of standard deviation was used to correct for varying group size (Biemann and Kearney, 2010). Comparability of the results to prior studies using the coefficient of variation (Allison, 1978) and uncorrected measures might be poor. Despite these limitations, the present study has provided new knowledge on the paths how TMT's properties are associated with firm performance. 


\section{References}

Abebe, M.A. (2010), “Top team composition and corporate turnaround under environmental stability and turbulence", Leadership \& Organization Development Journal, Vol. 31 No. 3, pp. 196-212.

Allison, P.D. (1978), “Measures of inequality”, American Sociological Review, Vol. 43 No. 6, pp. $865-880$.

Barkema, H.G. and Shvyrkov, O. (2007), "Does top management team diversity promote or hamper foreign expansion?”, Strategic Management Journal, Vol. 28 No. 7, pp. 663-680.

Bell, S.T., Villado, A.J., Lukasik, M.A., Belau, L. and Briggs, A.L. (2011), “Getting specific about demographic diversity variable and team performance relationships: A meta-analysis", Journal of Management, Vol. 37 No. 3, pp. 709-743.

Biemann, T. and Kearney, E. (2010), "Size does matter: How varying group sizes in a sample affect the most common measures of group diversity", Organizational Research Methods, Vol. 13 No. 3, pp. 582-599.

Boeker, W. (1997), "Strategic change: The influence of managerial characteristics and organizational growth", Academy of Management Journal, Vol. 40 No. 1, pp. 152-170.

Boone, C. and Hendriks, W. (2009), “Top management team diversity and firm performance: Moderators of functional-background and locus-of-control diversity", Management Science, Vol. 55 No. 2, pp. 165-180.

Bromiley, P. and Rau, D. (2016), "Social, behavioral, and cognitive influences on upper echelons during strategy process: A literature review”, Journal of Management, Vol. 42 No. 1, pp. 174-202.

Burns, D.C., Sale, J.T. and Stephan, J.A. (2008), “A better way to gauge profitability”, Journal of Accountancy, Vol. 206 No. 2, pp. 38-42.

Camelo, C., Fernández-Alles, M. and Hernández, A.B. (2010), "Strategic consensus, top management teams, and innovation performance", International Journal of Manpower, Vol. 31 No. 6, pp. 678-695.

Carpenter, M.A., Geletkanycz, M.A. and Sanders, W.G. (2004), "Upper echelons research revisited: Antecedents, elements, and consequences of top management team composition", Journal of Management, Vol. 30 No. 6, pp. 749-778.

Certo, S.T., Lester, R.H., Dalton, C.M. and Dalton, D.R. (2006), “Top management teams, strategy and financial performance: A meta-analytic examination”, Journal of Management Studies, Vol. 43 No. 4, pp. 813-839. 
Chen, H.-L. (2011), "Does board independence influence the top management team? Evidence from strategic decisions toward internationalization", Corporate Governance: An International Review, Vol. 19 No. 4, pp. 334-350.

DeChurch, L.A. and Mesmer-Magnus, J.R. (2010), “The cognitive underpinnings of effective teamwork: A meta-analysis", Journal of Applied Psychology, American Psychological Association, Vol. 95 No. 1, pp. 32-53.

von den Driesch, T., da Costa, M.E.S., Flatten, T.C. and Brettel, M. (2015), "How CEO experience, personality, and network affect firms' dynamic capabilities", European Management Journal, Vol. 33 No. 4, pp. 245-256.

Fairfield, P.M. and Yohn, T.L. (2001), "Using asset turnover and profit margin to forecast changes in profitability", Review of Accounting Studies, Vol. 6 No. 4, pp. 371-385.

Glunk, U., Heijltjes, M.G. and Olie, R. (2001), "Design characteristics and functioning of top management teams in Europe", European Management Journal, Vol. 19 No. 3, pp. 291300.

Gonzalez-Mulé, E., Cockburn, B.S., McCormick, B.W. and Zhao, P. (2020), “Team tenure and team performance: A meta-analysis and process model”, Personnel Psychology, Vol. 73 No. 1, pp. 151-198.

Hair, J.F., Black, W.C., Babin, B.J. and Anderson, R.E. (2015), Multivariate Data Analysis, 7th ed., Dorling Kindersley, Delhi.

Hambrick, D.C. (2007), "Upper echelons theory: An update”, Academy of Management Review, Vol. 32 No. 2, pp. 334-343.

Hambrick, D.C., Geletkanycz, M.A. and Fredrickson, J.W. (1993), “Top executive commitment to the status quo: Some tests of its determinants”, Strategic Management Journal, Vol. 14 No. 6, pp. 401-418.

Hambrick, D.C., Humphrey, S.E. and Gupta, A. (2015), "Structural interdependence within top management teams: A key moderator of upper echelons predictions", Strategic Management Journal, Vol. 36 No. 3, pp. 449-461.

Hambrick, D.C. and Mason, P.A. (1984), "Upper echelons: The organization as a reflection of its top managers", The Academy of Management Review, Vol. 9 No. 2, pp. 193-206.

Harrison, D.A. and Klein, K.J. (2007), "What's the difference? Diversity constructs as separation, variety, or disparity in organizations", Academy of Management Review, Vol. 32 No. 4, pp. $1199-1228$.

Hiebl, M.R.W. (2014), "Upper echelons theory in management accounting and control research", Journal of Management Control, Vol. 24 No. 3, pp. 223-240. 
Hofstede, G. (2001), Culture's Consequences: Comparing Values, Behaviors, Institutions and Organisations Across Nations, 2nd ed., Sage Publications, Thousand Oaks.

Homberg, F. and Bui, H.T. (2013), “Top management team diversity: A systematic review”, Group \& Organization Management, Vol. 38 No. 4, pp. 455-479.

Kihn, L.-A. (2010), "Performance outcomes in empirical management accounting research: Recent developments and implications for future research", International Journal of Productivity and Performance Management, Vol. 59 No. 5, pp. 468-492.

van Knippenberg, D., De Dreu, C.K.W. and Homan, A.C. (2004), "Work Group Diversity and Group Performance: An Integrative Model and Research Agenda.”, Journal of Applied Psychology, Vol. 89 No. 6, pp. 1008-1022.

Kozlowski, S.W.J. and Ilgen, D.R. (2006), "Enhancing the Effectiveness of Work Groups and Teams", Psychological Science in the Public Interest, Vol. 7 No. 3, pp. 77-124.

Kraiczy, N.D., Hack, A. and Kellermanns, F.W. (2015), “The Relationship Between Top Management Team Innovation Orientation and Firm Growth: The Mediating Role of Firm Innovativeness", International Journal of Innovation Management, Vol. 19 No. 1, pp. 1-24. Lawrence, B.S. (1997), “The black box of organizational demography”, Organization Science, Vol. 8 No. 1, pp. 1-22.

Naranjo-Gil, D. and Hartmann, F. (2006), "How top management teams use management accounting systems to implement strategy", Journal of Management Accounting Research, Vol. 18 No. 1, pp. 21-53.

Naranjo-Gil, D., Hartmann, F. and Maas, V.S. (2008), “Top management team heterogeneity, strategic change and operational performance", British Journal of Management, Vol. 19 No. 3, pp. 222-234.

Ng, T.W.H. and Feldman, D.C. (2013), "How do within-person changes due to aging affect job performance?”, Journal of Vocational Behavior, Vol. 83 No. 3, pp. 500-513.

Nielsen, B.B. and Nielsen, S. (2013), “Top management team nationality diversity and firm performance: A multilevel study", Strategic Management Journal, Vol. 34 No. 3, pp. 373382.

Nielsen, S. (2010a), “Top management team diversity: A review of theories and methodologies", International Journal of Management Reviews, Vol. 12 No. 3, pp. 301-316.

Nielsen, S. (2010b), "Top management team internationalization and firm performance: The mediating role of foreign market entry”, Management International Review, Vol. 50 No. 2 , pp. 185-206.

Nissim, D. and Penman, S.H. (2001), "Ratio analysis and equity valuation: From research to practice", Review of Accounting Studies, Vol. 6 No. 1, pp. 109-154. 
Pelled, L.H. (1996), "Demographic diversity, conflict, and work group outcomes: An intervening process theory”, Organization Science, Vol. 7 No. 6, pp. 615-631.

Roh, H., Chun, K., Ryou, Y. and Son, J. (2019), “Opening the Black Box: A Meta-Analytic Examination of the Effects of Top Management Team Diversity on Emergent Team Processes and Multilevel Contextual Influence”, Group \& Organization Management, Vol. 44 No. 1, pp. 112-164.

Schreiber, J.B., Nora, A., Stage, F.K., Barlow, E.A. and King, J. (2006), "Reporting structural equation modeling and confirmatory factor analysis results: A review", The Journal of Educational Research, Vol. 99 No. 6, pp. 323-338.

Selling, T.I. and Stickney, C.P. (1989), "The effects of business environment and strategy on a firm's rate of return on assets", Financial Analysts Journal, Vol. 45 No. 1, pp. 43-52.

Senior, B. and Swailes, S. (2004), "The dimensions of management team performance: A repertory grid study", International Journal of Productivity and Performance Management, Vol. 53 No. 4, pp. 317-333.

Shen, W. and Cannella, A.A. (2002), "Revisiting the performance consequences of CEO succession: The impacts of successor type, postsuccession senior executive turnover, and departing CEO tenure", Academy of Management Journal, Vol. 45 No. 4, pp. 717-733.

Smith, A., Houghton, S.M., Hood, J.N. and Ryman, J.A. (2006), "Power relationships among top managers: Does top management team power distribution matter for organizational performance?", Journal of Business Research, Vol. 59 No. 5, pp. 622-629.

Soliman, M.T. (2008), "The use of DuPont analysis by market participants", Accounting Review, Vol. 83 No. 3, pp. 823-853.

Sturman, M. (2003), "Searching for the Inverted U-Shaped Relationship Between Time and Performance: Meta-Analyses of the Experience/Performance, Tenure/Performance, and Age/Performance Relationships”, Journal of Management, Vol. 29 No. 5, pp. 609-640.

Wiersema, M.F. and Bantel, K.A. (1992), “Top management team demography and corporate strategic change", Academy of Management Journal, Vol. 35 No. 1, pp. 91-121.

Yamak, S., Nielsen, S. and Escribá-Esteve, A. (2014), “The role of external environment in upper echelons theory: A review of existing literature and future research directions", Group \& Organization Management, Vol. 39 No. 1, pp. 69-109. 


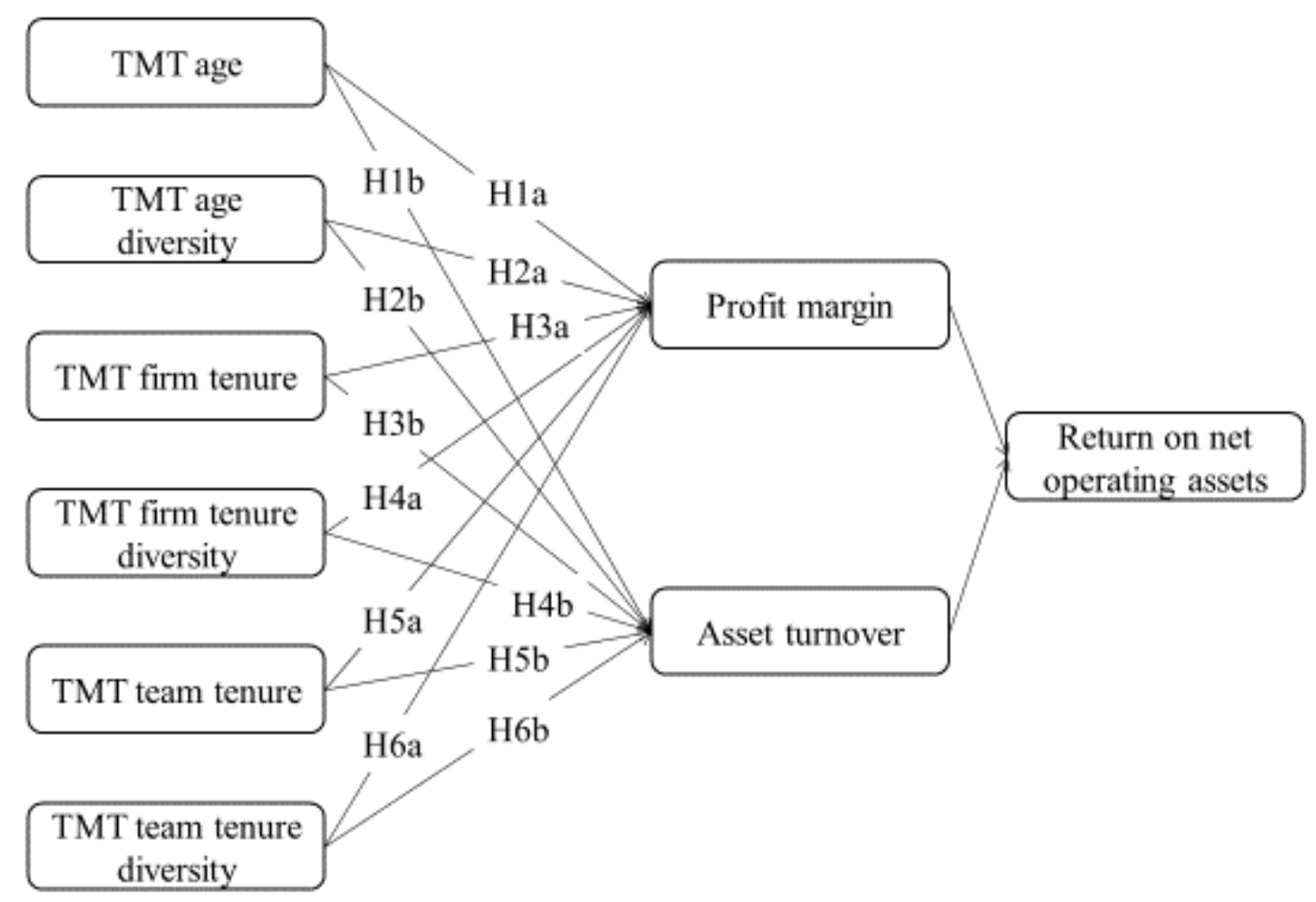

Figure 1. Theoretical model and hypotheses 
Table I

Demographic data on firms and TMTs

$\mathrm{n} \quad \%$

Panel A. Industry classification (ICB)

Basic materials

$10 \quad 11.2$

Consumer goods

$13 \quad 14.6$

Consumer services

$10 \quad 11.2$

Industrials

$40 \quad 44.9$

Technology

$16 \quad 18.0$

Total

89

Panel B. Firm size (personnel)

\begin{tabular}{lrr}
$0-250$ & 8 & 9.0 \\
$251-500$ & 15 & 16.9 \\
$501-1.000$ & 18 & 20.2 \\
$1,001-5,000$ & 21 & 23.6 \\
$5,001-10,000$ & 13 & 14.6 \\
$10,001-$ & 14 & 15.7 \\
Total & 89 & \\
\hline
\end{tabular}


Table II

Descriptive statistics and Pearson correlations $(\mathrm{n}=320)$

\begin{tabular}{lrrrrrrrrrrr}
\hline & Mean & \multicolumn{1}{l}{ SD } & \multicolumn{1}{c}{1} & 2 & 3 & 4 & 5 & 6 & 7 & 8 & 9 \\
\hline 1. Age & 47.51 & 3.40 & 1 & & & & & & & \\
2. Age diversity & 6.11 & 1.84 & -0.05 & 1 & & & & & & \\
3. Firm tenure & 8.97 & 4.54 & 0.51 & -0.02 & 1 & & & & & \\
4. Firm tenure diversity & 7.39 & 3.38 & 0.48 & -0.02 & 0.72 & 1 & & & & \\
5. Team tenure & 2.43 & 1.85 & 0.22 & -0.07 & 0.46 & 0.14 & 1 & & & \\
6. Team tenure diversity & 1.40 & 1.29 & 0.13 & 0.15 & 0.40 & 0.27 & 0.66 & 1 & & \\
7. PM, \% & 3.98 & 9.01 & 0.04 & -0.04 & 0.17 & 0.16 & 0.24 & 0.23 & 1 & \\
8. ATO & 2.11 & 1.23 & -0.15 & -0.24 & -0.01 & -0.11 & 0.11 & -0.06 & 0.10 & 1 \\
9. RNOA, \% & 9.56 & 16.93 & -0.07 & -0.11 & 0.11 & 0.10 & 0.16 & 0.10 & 0.78 & 0.50 & 1 \\
\hline
\end{tabular}

All correlations above $r=0.10$ significant at $p<0.05$. 
Table III

Results of the structural model

\begin{tabular}{|c|c|c|c|c|}
\hline & \multirow{3}{*}{ Variable } & \multicolumn{3}{|c|}{ Standardized estimates } \\
\hline & & \multicolumn{3}{|l|}{ Path to: } \\
\hline & & PM & ATO & RNOA \\
\hline H1a: TMT age is negatively associated with firm PM & Age & -0.09 & & \\
\hline H1b: TMT age is negatively associated with firm ATO & Age & & $-0.22 * * *$ & \\
\hline H2a: TMT age diversity is negatively associated with firm PM & Age diversity & -0.03 & & \\
\hline $\mathrm{H} 2 \mathrm{~b}$ : TMT age diversity is (strong) negatively associated with firm ATO & Age diversity & & $-0.19 * * *$ & \\
\hline H3a: TMT firm tenure is negatively associated with firm PM & Firm tenure & -0.01 & & \\
\hline $\mathrm{H} 3 \mathrm{~b}$ : TMT firm tenure is positively associated with firm ATO & Firm tenure & & $0.19 * *$ & \\
\hline H4a: TMT firm tenure diversity is positively associated with firm PM & Firm tenure diversity & 0.11 & & \\
\hline H4b: TMT firm tenure diversity is negatively associated with firm ATO & Firm tenure diversity & & $-0.15 * *$ & \\
\hline H5a: TMT team tenure is (strong) positively associated with firm PM & Team tenure & $0.16 * *$ & & \\
\hline H5b: TMT team tenure is positively associated with firm ATO & Team tenure & & $0.17 * *$ & \\
\hline H6a: TMT team tenure diversity is positively associated with firm PM & Team tenure diversity & 0.07 & & \\
\hline \multirow[t]{8}{*}{ H6b: TMT team tenure diversity is negatively associated with firm ATO } & Team tenure diversity & & $-0.14 *$ & \\
\hline & TMT size & $0.13 * *$ & -0.01 & \\
\hline & Firm size & 0.01 & $0.13 *$ & \\
\hline & Industry 1 & -0.08 & $-0.34 * * *$ & \\
\hline & Industry 2 & 0.09 & $-0.16^{* * *}$ & \\
\hline & Industry 3 & $0.13 * *$ & -0.07 & \\
\hline & Industry 5 & 0.03 & $-0.11 * *$ & \\
\hline & Year 2 & $-0.26 * * *$ & $-0.14 * *$ & \\
\hline
\end{tabular}




$\begin{array}{lrrr}\text { Year 3 } & -0.07 & -0.04 & \\ \text { Year 4 } & -0.06 & 0.02 & \\ \text { PM, \% } & & & 0.74 * * * \\ \text { ATO } & & & 0.43^{* * * *}\end{array}$

$\mathrm{X}^{2}=37.17, \mathrm{df}=16, \mathrm{p}=0.002, \mathrm{CFI}=0.99, \mathrm{NFI}=0.98, \mathrm{RMSEA}=0.064, \mathrm{SRMR}=0.013$

$* \mathrm{p}<.10, * * \mathrm{p}<.05, * * * \mathrm{p}<.01$ 